\title{
Psiquiatria e criminologia na Justiça Penal: os Tribunais do Júri e de Apelação do Distrito Federal, década de 1930
}

\author{
Psychiatry and criminology in Criminal Justice: \\ Jury Trial Courts and Appellate Courts in the Federal District \\ of Rio de Janeiro, during the 1930s
}

\author{
Allister Andrew Teixeira \\ Dias \\ Doutorando, Programa de Pós- \\ graduação em História das Ciências \\ e da Saúde/Casa de Oswaldo Cruz/ \\ Fiocruz. \\ Avenida Brasil, 4036, sala 420 \\ 21040-361 - Rio de Janeiro - RJ \\ - Brasil \\ allisterdias@hotmail.com
}

DIAS, Allister Andrew Teixeira. Psiquiatria e criminologia na Justiça Penal: os Tribunais do Júri e de Apelação do Distrito Federal, década de 1930. História, Ciências, Saúde - Manguinhos, Rio de Janeiro, v.22, n.3, jul.-set. 2015, p.1033-1041.

Resumo

Parte de uma pesquisa sobre o debate médico-criminológico no Brasil dos anos de 1930 e 1940, esta nota de pesquisa analisa alguns usos e críticas, entre certos juristas de importante atuação na cidade do Rio de Janeiro nos anos 1930, de argumentos de natureza psiquiátrica e criminológica. Tais magistrados, nesse contexto, tenderam a ter significativa erudição psiquiátrica e criminológica, apesar de toda heterogeneidade, pluralidade e diferenças de perspectivas existentes entre eles. Selecionamos dois espaços principais para análise da atuação desses juristas: o Tribunal de Apelação do Distrito Federal e o Tribunal do Júri.

Palavras-chave: criminologia; psiquiatria; magistrados; tribunal do júri; pensamento autoritário.

\section{Abstract}

As part of a research study on the 1930s and 1940s medical-criminological debate in Brazil, this research paper analyzes some of the uses and criticisms of arguments of a psychiatric and criminological nature, among certain jurists who carried out important work in the city of Rio de Janeiro during the 1930 s. In this context, these magistrates, tended to have significant psychiatric and criminological knowledge, in spite of all the heterogeneity, plurality and differences in perspectives that existed among them. We selected two principal areas to conduct an analysis of the activities of these jurists: the Appellate Court of the Federal District of Rio de Janeiro and Jury Trial Courts.

Keywords: criminology; psychiatry; magistrates; jury trials; authoritarian thinking.

http://dx.doi.org/10.1590/S0104-59702015000300022 
A pesquisa de doutorado, ${ }^{1}$ da qual esta nota de pesquisa é um retrato de momento, investiga os meandros dos debates médico-penais na cidade do Rio de Janeiro nas décadas de 1930 e 1940, com foco nos discursos sobre a natureza e o destino social do "homem criminoso" e suas possíveis "responsabilidade" penal e "periculosidade" social. Optamos por adentrar esse contexto discursivo e de debate público por meio de textos variados - livros, artigos, jurisprudência, laudos e pareceres psiquiátricos - publicados por médicos e juristas, autointitulados "criminologistas", sobretudo aqueles constantes em dois dos principais periódicos voltados para questões criminais do período: os Arquivos do Manicômio Judiciário do Rio de Janeiro (fundado em 1930) e a Revista de Direito Penal (fundada em 1933). Aqui, especificamente, realizar-se-á uma apreciação dos usos e críticas, entre alguns juristas em atuação nos Tribunais de Apelação e do Júri do Distrito Federal, durante a década de 1930, de laudos e argumentos psiquiátrico-criminológicos em suas decisões jurisprudenciais.

Cabe lembrar, inicialmente, que a Justiça Criminal brasileira, por variados fatores, sobre os quais não há espaço aqui para reportar, deu margem para o florescimento crescente de preocupações, entre os magistrados, em compreender a personalidade dos "criminosos"a fim de obter um melhor esclarecimento dos seus delitos. Os magistrados desse contexto, portanto, assim como em outras realidades nacionais (sobretudo as latinas de base inquisitorial), tenderam a ser bem informados criminologicamente e com "concepções psicologizantes" (Weijers, 2004, p.216), apesar de toda heterogeneidade, pluralidade e diferenças de perspectivas.

\section{O Tribunal do Júri do Distrito Federal}

O Júri foi instituição muito criticada no decorrer da história por parcelas significativas da intelectualidade brasileira. Em fins do século XIX, o jurista João Vieira de Araújo pedia a abolição dessa instituição, pois, a seu ver, ela coroava a "impunidade" e a "irracionalidade" com julgamentos que passavam ao largo do "conhecimento exato da natureza real do delinquente" (Alvarez, 2002, p.691). Essa foi a tônica subsequente, ainda mais entre os adeptos - relativos ou irrestritos - do genericamente chamado "positivismo criminológico", para os quais o julgamento deveria ser uma "apreciação técnica" realizada por um "corpo de especialistas, médicos, psiquiatras, antropólogos e criminólogos" (Carrara, 1998, p.114-115); uma questão de competência, não de "soberania popular". Nas palavras de Afrânio Peixoto (1916, p.354-356), em texto da década de 1910, o Júri era uma instituição arcaica e precária, com jurados incompetentes e sem capacidade técnica em matéria de psicopatologia e criminologia. O próprio Peixoto, muitos anos depois, em 1935, protagonizou uma situação interessante ao se recusar a compor um júri popular devido às suas "convicções científicas" (Caulfield, 2000, p.177).

Nas décadas de 1930 e 1940, o jurista Nelson Hungria foi um dos maiores críticos da forma como o Tribunal do Júri operava, mas com um foco diferente do de Peixoto, por exemplo. Para Hungria, os jurados se deixavam levar por qualquer retórica "pseudocientífica" (antropologia criminal, psicanálise, endocrinologia etc.), fosse utilizada por advogados, fosse por médicos, quando chamados à tribuna como peritos psiquiatras para avaliar o estado mental de certos criminosos (Sontag, 2009, p.274). No mesmo contexto de debate, o advogado e jornalista Evaristo de Morais clamava pela instituição desde o início do século, ressaltando sua importância como 
instrumento democrático (Mendonça, 2007, p.144). Roberto Lyra, um dos principais juristas das décadas de 1930 e 1940, do outro lado da tribuna, como promotor, também defendia a instituição no seu caráter democrático, e no acerto da maior parte de suas decisões em prol da defesa da sociedade contra os criminosos. Ambos, todavia, sinalizavam para a necessidade de reforma da instituição, sobretudo no que tangia a critérios mais rigorosos para a seleção dos jurados.

Magarinos Torres, um magistrado de atuação bastante destacada no período, presidente e um dos fundadores da Sociedade Brasileira de Criminologia (1933), considerava que as decisões do Júri eram de extremo bom senso, mesmo nos polêmicos "crimes passionais". Para ele, os juízes leigos sabiam muito bem o que faziam, deixando-se levar pelo relevante critério da "temibilidade"/"periculosidade" (ou ausência dela) dos uxoricidas (homens que matam as mulheres), critério que, aliás, teve seu nascedouro médico-penal na produção intelectual da chamada Escola Criminológica Positivista Italiana. Magarinos afirmava que os jurados decidiam "conforme (houvesse) ou não conveniência social na punição, segundo a temibilidade ou perversidade revelada" pelos criminosos, realizando correta política criminal (Prando, 2010, p.14).

Como ficaria o saber psiquiátrico-criminológico no interior do Júri, e qual seria seu papel na legitimação ou deslegitimação da instituição? Ary Azevedo foi juiz presidente do Júri do Distrito Federal do início da década de 1930 até 1946. Em texto de 1939, posicionou-se de forma categórica acerca da relevância dos saberes e práticas periciais psiquiátricas no processo penal da cidade (Azevedo, 1939, p.233-240). No seu entendimento, a reorganização judiciária (decreto n.16.273 de 20 de dezembro de 1923)² ocorrida no governo Arthur Bernardes foi bastante profícua ao determinar a obrigatoriedade das perícias psiquiátricas em casos em que a dirimente da "completa perturbação dos sentidos e da inteligência"3 fosse acionada, sobretudo pelas defesas, para a apreciação dos jurados no tribunal popular. Durante sete anos de vigência desse princípio (1923-1930), todas as decisões do Júri em casos em que aquela dirimente (dispositivo jurídico que pode inocentar ou diminuir a sanção penal) do Código Penal estava em jogo foram consoantes com os laudos lavrados por psiquiatras e médicoslegistas. Todavia, Magarinos Torres, presidente do Júri no ano de 1930, segundo Azevedo, por "motivos não ponderáveis" que vinham da alta cúpula do Governo Provisório, "suprimiu a obrigatoriedade desses exames" (Azevedo, 1939, p.235). Apesar disso, os exames continuaram na quase totalidade dos "réus de competência do Júri" que evocavam a dirimente, por toda a década de 1930.

Azevedo deixava um recado claro para os reformadores das leis penais do país: os exames psiquiátricos, tanto quanto os conhecimentos e esclarecimentos por eles trazidos para a Justiça Criminal, eram necessários para a sobrevivência do Tribunal do Júri e da legitimidade de suas decisões.Por exemplo, para Azevedo, o Júri precisava de laudos como aqueles que continham a rubrica de Heitor Carrilho. ${ }^{4}$ No seu ponto de vista, Carrilho era a "maior autoridade em assuntos de psiquiatria forense" do Brasil, logo, qualquer apreciação sua acerca de um caso constituía prova significativa a ser considera pelos juízes, tanto os leigos como os togados (Azevedo, 1938, p.59-60).

Como é sabido, com o golpe do Estado Novo, a "cultura política nacionalista-autoritária"passou a "fornecer a rationale" das políticas de Estado (Hollanda, 2009, p.131-134). 
Francisco Campos, como ministro da Justiça, era parte constitutiva do núcleo político ideológico do Estado Novo. Na sua retórica, as leis e instituições jurídicas deveriam se adaptar ao tempo e ao país (Jasmin, 2007, p.233). O Júri, nesse sentido, deveria ser reestruturado, e esse foi o papel da Lei do Júri de 1938, cuja redação esteve sob seus auspícios. Tal lei (Brasil, 5 jan. 1938) contemplou todos os aspectos do pensamento autoritário: antidemocrática, estatista, desmobilizacionista e realista-tecnicista (pautada na retórica de que somente alguns indivíduos tinham o verdadeiro conhecimento da realidade tal como ela é, no caso, os juízes togados) (Brandão, 2005, p.246). Para Campos, o Júri na forma como vinha operando era sinônimo de caos, e muito pouca diferença fazia a atuação de saberes científicos ali, psiquiátricos e/ou criminológicos. A auscultação do "populacho" que o Júri representava não era coerente com um país no qual uma elite técnica deveria governar; indo além, os códigos morais e sociais que de fato guiaram as decisões do Júri ao longo da história - não poderiam suplantar o código positivado.

Segundo Campos (1940, p.230), com a nova lei, as coisas se acertariam: "a aplicação da justiça penal pelo júri deixa de ser uma abdicação, para ser uma delegação do Estado, que se reserva o direito de ajustá-la à feição do interesse social". Ou seja, o ministro da Justiça de Vargas entendia que a soberania das decisões do Júri - uma forma de aplicação da Justiça Penal - representava a ausência do Estado em questões cruciais para seu próprio equilíbrio, como eram as questões criminais; somente com a nova feição fornecida pela lei de 1938 o Júri corresponderia às prerrogativas modernas de "defesa" e "interesse social", porquanto estaria sob o controle do Estado representado pelos juízes não leigos, na sua fiscalização do direito popular de julgar. Na prática, com a lei, a "soberania do júri" estava relativizada em função do princípio, ali contemplado, da "reformabilidade das decisões do Júri pelos Tribunais de Apelação" (Campos, 1940, p.232). Os juízes de carreira, técnicos do saber jurídico, poderiam, nesse sentido, decidir se a forma como os jurados - juízes leigos, sem saber técnico - usaram os argumentos psiquiátricos nas suas decisões era correta ou não.

\section{O Tribunal de Apelação do Distrito Federal: e os saberes médico-criminológicos}

Fica evidente em algumas discussões jurisprudenciais inscritas no Tribunal de Apelação do Distrito Federal (TADF) ao longo da década de 1930 o quanto alguns magistrados prezavam o informe de laudos periciais bem fundados num atualizado e bem especializado saber psiquiátrico-criminológico, como Ary Azevedo reivindicava do lugar de presidente do Tribunal do Júri, como vimos. Exames assinados por "peritos não especializados" não eram bem-vistos. As categorias e definições desses exames deveriam ter uma correspondência exata com o que havia de mais contemporâneo na literatura psiquiátrica (Apelação criminal n.2.251, 1939, p.108-114). Nesse sentido, os próprios magistrados corroboravam o clamor "ninarodriguiano" pela especialização dos peritos médico-legais, primordialmente aquele consagrado em As raças humanas e a responsabilidade penal (1894). Nina Rodrigues (citado em Ferla, 2009, p.173) enfatizava que os médicos-legistas das polícias e das cadeias deveriam conhecer muito de psiquiatria, para que um dia se consagrasse seu ideal de exames em todos os delinquentes presos: "a psiquiatria forense é a pedra angular da perícia médica e a exigência da freniatria 
na instrução do médico perito a condição de sua capacidade para a compreensão do serviço que dele exige a justiça".

Magarinos Torres, significativamente, também era defensor da participação do saber médico no processo penal. Apoiou, em muitos momentos, a autoridade médica dos laudos de Heitor Carrilho. O caso de S.N. foi notório na jurisprudência da cidade. S.N., indivíduo branco, de 28 anos, sofrendo de "blenorragia", utilizou para dor "brometo de cânfora" - por indicação médica e, em seguida, "perdeu os sentidos" e agrediu a socos o tio de uma amásia, matando-o (Carrilho, $1^{\circ}$ sem. 1930, p.209-217). Examinando o indivíduo no Hospital do Exército, Carrilho e o médico M.C. Rego (médico da Polícia) concluíram tratar-se de um indivíduo normal que perdeu a consciência numa "impulsão epileptoide" decorrente do uso do "brometo de cânfora". Carrilho e Rego afirmaram o quanto foi genuína a "completa perturbação dos sentidos e da inteligência" nesse caso. Magarinos Torres ( $1^{\circ}$ sem. 1930, p.228-231), na sua sentença de 27 de novembro de 1930, defendeu categoricamente as conclusões dos médicos. Para ele, toda decisão judiciária acerca da "completa perturbação dos sentidos e da inteligência" deveria levar em conta a opinião científica dos médicos peritos, na medida em que ainda não se chegara à fase do direito penal prevista por Jimenez de Asúa, na qual "os novos juízes não serão juristas senão antropólogos, psicólogos e psiquiatras, verdadeiros médicos sociais, em que o conhecimento de que menos precisem será justamente o direito" (Torres, $1^{\circ}$ sem. 1930, p.228-231). Em um caso como esse, nada mais justo, para o magistrado, do que o "inevitável louvar-se na palavra dos cientistas" (Torres, $1^{\circ}$ sem. 1930, p.230).

Em outras circunstâncias, para Magarinos Torres (1932, p.102-105), poderia nortear as decisões judiciais em casos similares à concepção de Carrilho, segundo a qual criminosos passionais uxoricidas que tentavam de fato se matar, depois de matar ou atentar contra a vida das mulheres, revelavam séria perturbação mental no momento do crime e, portanto, deveriam ser tidos como inimputáveis. Outros desembargadores, como Cesário Pereira, Edgar Costa e Vicente Piragipe, também destacavam o "valor" dos laudos de Carrilho. No caso de J.V.P., que matou a tiros a namorada no dia 15 de maio de 1931, tentando em seguida se matar com um tiro no peito (Costa, 1932, p.99-101), tais desembargadores reconheceram, com base na perspectiva de Carrilho, "acatado psiquiatra", que a tentativa séria de suicídio caracterizava uma "completa perturbação dos sentidos e da inteligência".

Não somente os exames eram prezados, mas também todo um conjunto de argumentos médico-criminológicos. Os chamados "crimes passionais" demandavam bastante operacionalização de argumentos desse tipo. Muitos desembargadores confirmaram decisões do Júri ou propuseram novo julgamento de "passionais" (homens ou mulheres) com base no argumento de "dor moral", por exemplo, noção proveniente de criminalistas e médicos italianos e alemães, que contemplava a força de sentimentos "naturais" - impulsos superiores-, como o maternal ou paternal, na razão de ser de alguns crimes (Apelação criminal 3.117, $1^{\circ}$ sem. 1930, p.79-87). Ou mesmo, criminosos comprovadamente "hiperemotivos", de "temperamento nervoso", acometidos de "ciúme mórbido", ou ainda indivíduos em estado avançado de tabes dorsalis, deveriam ser considerados inimputáveis (Apelação criminal 2.601, 1931, p.87-93), como há muito vinham pregando alguns psiquiatras.

Acontece, entretanto, que outros magistrados em atuação nesse mesmo espaço também questionavam bastante as absolvições dos passionais e o uso de argumentos psiquiátricos, 
criminológicos e psicológicos para tanto. Sem dúvida, o principal deles era Nelson Hungria. Em sentença de 1931, além de desconstruir o argumento da "honra masculina", apontou que a psiquiatria era uma das principais culpadas por absolvições de homens que matavam suas mulheres (Hungria, 1931, p.95-98). Na sua percepção, a literatura psiquiátrica "lobrigava o patologismo nas mais fugidias discordâncias de condutas", contribuindo para abrir as "portas das prisões a uma privilegiada chusma de sicários e rapinantes" (Hungria citado em Sontag, 2009, p.273).

Não há dúvidas de que Carrilho era a corporificação mais forte dessa psiquiatria questionada por Hungria. Não obstante, por outro lado, em certas ocasiões, Hungria respeitava a psiquiatria enquanto adversário científico à altura do direto penal puro que propugnava (Ferla, 2009, p.377). Ele inclusive criticava magistrados que não dominavam noções psiquiátricas mais consolidadas. Em sua opinião, os magistrados deveriam rechaçar a psiquiatria por dentro, no que ela possuía de frágil, porém, naquilo que apresentava "lições unívocas", deveria ser respeitada e conhecida. Não era o caso das questões trazidas pelas abordagens endocrinológicas ou psicanalíticas, por exemplo. No campo de debates acerca da responsabilidade penal, a palavra final tinha de ser a do juiz, insubmisso a laudos. Para ele, "a psiquiatria ao deixar o templo de Esculápio para entrar no Temis, há de curvar-se ante os altares e rezar nos seus ritualis libri" (Hungria citado em Ferla, 2009, p.378).

Um caso muito interessante, debatido no bojo do TADF, logo após a promulgação da Lei do Júri de 1938, além de espaço de polêmica em torno dessa lei, expressou também as múltiplas facetas que os laudos e saberes psicocriminológicos, enquanto elementos integrantes do processo penal, poderiam assumir entre os magistrados.

No dia 11 de abril de 1939, o Ministério Público entrou com uma apelação pedindo a reforma da sentença do Júri no caso de um famoso "fraudador" de nome R.G. Ele tinha acabado de ser absolvido pelo tribunal popular. Para o desembargador José Duarte, relator do caso no TADF, a nova Lei do Júri adveio como algo altamente relevante, porque dava aos "juízes togados" a liberdade de proceder a reforma direta de uma decisão do Júri (Apelação criminal 62, 1939, p.94-102). Os togados, no seu ponto de vista, seriam mais capazes de apreciar provas complexas. Com efeito, para ele a "revolução fascista" - ao demonstrar os "danos do democratismo" - foi responsável por jogar luz nos "erros" crassos que ao longo do tempo minaram muito da legitimidade do Júri. O Brasil seguiu esse caminho. Todavia, seu colega magistrado Carlos L. de Almeida discordava totalmente dessa interpretação. Para ele, o Tribunal Superior não podia "anular" o tribunal popular do Júri.

No caso específico, a polêmica de fundo advinha do papel atribuído por esses magistrados individualmente aos laudos psiquiátricos apresentados aos jurados. Para o relator, os laudos eram sem valor, porque subsidiados quase exclusivamente por uma interpretação psicanalítica; na sua perspectiva a psicanálise não tinha respaldo científico para embasar um laudo a ser apresentado ao Júri. Para José Duarte, R.G. era um grande "fraudador", e indivíduo desse tipo mentia em "interesse próprio", devendo sempre ser considerado responsável por seus atos. Já para Carlos L. de Almeida, a absolvição estava "plenamente justificada", na medida em que os exames de sanidade pelos quais passou R.G. concluíram pela sua "anormalidade psíquica". Para este último magistrado, as observações pelas quais R.G. passou no Hospital Nacional de Alienados foram muito bem fundadas, mesmo que informadas na psicanálise. Perdeu a briga, 
contudo. A maioria dos desembargadores votou junto com o relator no "acordão" desse caso, não reconhecendo a validade dos laudos.

\section{Considerações finais}

Os discursos científicos sobre o crime e o criminoso são espaços atravessados pelo feixe de vários saberes, com dinâmica interna mutante, marcados por tensões e "fricções" (Skalevag, 2006). Os saberes psicocriminológicos foram elementos muito presentes nos Tribunais do Júri e de Apelação, no contexto do Rio de Janeiro da década de 1930. Em alguns atos de fala de alguns magistrados, tais saberes ajudavam no processo penal e melhor informavam os jurados e os juízes sobre a natureza dos criminosos sob seus julgamentos. Em outros, porém, era salientada a influência nociva do que consideravam conhecimentos pseudocientíficos, seja entre juízes leigos ou juristas de formação. Ou seja, os posicionamentos eram plurais entre os magistrados. Nesse período, a produção de saberes sobre o homem criminoso já não possuía um lugar profissional fixo, mas sim vários espaços possíveis, os quais merecem atenção de análises históricas contextualistas e desnaturalizadoras.

No que tange aos debates sobre o Júri, sérias questões políticas estavam envolvidas, imbricando-se com as expectativas e os debates científicos. Um ponto fulcral era a ilegitimidade de participação no processo penal de indivíduos sem capacidade para apreciação criminológica da personalidade dos delinquentes. Pelo que é possível depreender da jurisprudência até aqui analisada, e pelos "atos de fala" de alguns juristas e médicos voltados para a questão criminal do período, as décadas de 1920 e 1930 marcam esforços por parte da magistratura de operar de maneira significativa com os variados saberes médico-criminológicos, inclusive encontrandos - principalmente os veiculados por especialistas - a legitimidade das decisões do Júri.

A jurisprudência do Tribunal de Apelação, em casos de "completa perturbação dos sentidos e da inteligência", denota esse fato. Isso não se deu sem fortes ruídos. Nesse contexto, Nelson Hungria constituiu-se num grande crítico do que chamava de abordagem "biologicista, criminofílica", pautada no intercurso de outros saberes no bojo do direito penal que se queria "puro" e "normativo".

O fechamento do regime em 1937 teve implicações no âmbito do processo penal, colocando outros termos para os usos dos saberes médico-criminológicos. Os magistrados, com a lei de 1938, controlando as sensibilidades e representações dos jurados leigos, tinham o poder de definir o estatuto de prova dos laudos e, portanto, validar ou não os conhecimentos "psi" por detrás deles. Cabe investigar, no desenvolver da pesquisa, além de outras questões, o quanto os saberes criminológicos de verniz mais médico fizeram parte da formação da geração de juristas que teve atuação sistemática na década de 1930, década fundamental para compreender a estruturação penal e penitenciária do Brasil republicano. É preciso verificar, ainda, em que medida essas ideias fundamentaram e/ou foram rechaçadas na construção de discursos e políticas acerca das causas e possíveis medidas de prevenção ao crime e, ademais, focando nas temáticas da responsabilidade penal e da periculosidade social do criminoso, compreender a justa dimensão dos saberes psiquiátricos no debate público sobre o crime nesse período. 


\section{NOTAS}

${ }^{1}$ Pesquisa de doutorado implementada, desde 2011, no Programa de Pós-graduação em História das Ciências e da Saúde (PPGHCS), Casa de Oswaldo Cruz (Fiocruz), sob o título provisório de "Arquivos de ciência, crime e loucura: Heitor Carrilho e o debate médico-penal na cidade do Rio de Janeiro, 1930-1954", com orientação do professor Flávio Coelho Edler e financiamento da Coordenação de Aperfeiçoamento de Pessoal de Nível Superior. Esta nota de pesquisa é um aprofundamento do texto apresentado na segunda Jornada de Pósgraduação em História das Ciências e da Saúde, realizada pelo PPGHCS em outubro de 2013, ao qual foi atribuído menção honrosa.

${ }^{2}$ Esse decreto reorganizou a Justiça no Distrito Federal. Entre os aspectos importantes a ressaltar, vale destacar a instituição dos "peritos" médicos como "funcionários auxiliares da Justiça" (artigo $3^{\circ}$, parágrafo $2^{\circ}$ ), formalizando e regulamentando a participação médica na Justiça Criminal. Os "médicos privativos" da Justiça passaram a ser, oficialmente, os médicos do Instituto Médico Legal, os professores de medicina legal da Faculdade de Medicina do Rio de Janeiro e os médicos da Assistência a Alienados (artigo 167); nas perícias de "indagação psiquiátrica" deveriam participar um "médico legista" do Instituto Médico Legal e um "especialista" da Assistência a Alienados, "de preferência o diretor médico do Manicômio Judiciário" (artigo 168), o que significava que, no período estudado, décadas de 1930 e 1940, Heitor Carrilho participou de boa parte das perícias de verificação do estado mental de acusados e condenados na Justiça Criminal no Distrito Federal. Por outro lado, como foi mencionado acima, o artigo 94 do mesmo decreto estabeleceu que, em casos sob apreciação do Júri, "nenhum quesito sobre qualquer enfermidade mental... com relação ao acusado, poderá ser proposto, desde que se não tenha realizado prévia perícia técnica no curso do processo" (Brasil, 20 dez. 1923).

${ }^{3}$ Segundo o Código Penal de 1890 (artigo 27, parágrafo $4^{\circ}$ ), vigente até 1941, mas com modificações, não poderiam ser considerados responsáveis pelos seus atos criminosos indivíduos que cometessem crimes em "estado de completa privação dos sentidos e da inteligência". Tal dispositivo deu ensejo a disputas seríssimas, tanto entre juristas, como entre médicos e juristas, e mesmo entre médicos, ao longo de toda Primeira República e década de 1930.

${ }^{4}$ Heitor Carrilho (1890-1954) foi diretor do Manicômio Judiciário do Rio de Janeiro de 1921 até sua morte, em 1954. Foi o médico de maior atuação no contexto do debate público médico-penal no Rio de Janeiro nos anos 1920, 1930 e 1940.

\section{REFERÊNCIAS}

ALVAREZ, Marcos César.

A criminologia no Brasil ou como tratar desigualmente os desiguais. Dados, v.45, n.4, p.677-704. 2002.

\section{APELAÇÃO CRIMINAL N.62.}

Jurisprudência. Apelação criminal n.62. Arquivos do Manicômio Judiciário do Rio de Janeiro, ano 10, p.94-102. 1939.

APELAÇÃO CRIMINAL N.2.251.

Jurisprudência. Apelação criminal n.2.251.

Arquivos do Manicômio Judiciário do Rio de Janeiro, ano 10, p.108-114. 1939.

APELAÇÃO CRIMINAL N.2.601.

Jurisprudência. Apelação criminal n.2.601.

Arquivos do Manicômio Judiciário do Rio de Janeiro, ano 2, p.87-93. 1931.

APELAÇÃO CRIMINAL N.3.117.

Jurisprudência. Apelação criminal n.3.117.

Arquivos do Manicômio Judiciário do Rio de Janeiro, ano 1, p.79-87. $1^{\circ}$ sem. 1930.

AZEVEDO, Ary.

A perícia psiquiátrica nos processos penais.
Arquivos do Manicômio Judiciário do Rio de Janeiro, ano 10, p.7-11. 1939.

AZEVEDO, Ary.

Jurisprudência. Sentença do juiz Ary de Azevedo Franco. Arquivos do Manicômio Judiciário do Rio de Janeiro, ano 9, p.59-60. 1938.

BRANDÃO, Gildo Marçal.

Linhagens do Pensamento Político Brasileiro.

Dados, v.48, n.2, p.231-269. 2005.

BRASIL.

Decreto n.167, de 5 de janeiro de 1938. Regula a instituição do Júri. Disponível em: http://www. planalto.gov.br/ccivil_03/decreto-lei/1937-1946/ Del0167.htm. Acesso em: 25 set. 2013. 5 jan. 1938.

BRASIL.

Decreto n.16.273, de 20 de dezembro de 1923. Reorganiza a Justiça do Distrito Federal. Disponível em: http://www2.camara.leg.br/ legin/fed/decret/1920-1929/decreto-16273-20dezembro-1923-509027-publicacaooriginal-1-pe. html. Acesso em: 23 set. 2013. 20 dez. 1923. 
CAMPOS, Francisco.

O Estado Nacional. Disponível em: http://www. ebooksbrasil.org/eLibris/chicocampos.html. Acesso em: 14 jan. 2013. (versão eBooksBrasil. com). 1940.

CARRARA, Sérgio.

Crime e loucura: o aparecimento do manicômio judiciário na passagem do século. Rio de Janeiro: EdUERJ; São Paulo: EdUSP. 1998.

CARRILHO, Heitor.

Laudos e documentos psiquiátrico-legais.

Arquivos do Manicômio Judiciário do Rio de Janeiro, ano 1, p.209-217. $1^{\circ}$ sem. 1930.

CAULFIELD, Sueann.

Em defesa da honra: moralidade, modernidade e Nação no Rio de Janeiro (1918-1940). Campinas: Editora da Unicamp. 2000.

COSTA, Edgar.

Jurisprudência. Apelação criminal n.3.534.

Arquivos do Manicômio Judiciário do Rio de Janeiro, ano 3, p.99-101. 1932.

FERLA, Luiz Antônio Coelho.

Feios, sujos e malvados sob medida: do crime ao trabalho, a utopia médica do biodeterminismo em São Paulo (1920-1945). São Paulo: Alameda. 2009.

HOLLANDA, Cristina Buarque de.

Modos de representação política: o experimento da Primeira República Brasileira. Belo Horizonte: Editora UFMG; Rio de Janeiro: Iuperj. 2009.

HUNGRIA, Nelson.

Jurisprudência. Sentença do juiz Nelson Hungria Hoffbauer. Arquivos do Manicômio Judiciário do Rio de Janeiro, ano 2, p.95-98. 1931.

JASMIN, Marcelo.

Mímesis e recepção: encontros transatlânticos do pensamento autoritário brasileiro da década de 1930. In: Feres Junior, João; Jasmin, Marcelo (Org.). História dos conceitos: diálogos transatlânticos. Rio de Janeiro: Ed. PUC-RIO, Loyola, Iuperj, p.229-239. 2007.

MENDONÇA, Joseli M. Nunes.

Evaristo de Moraes, tribuno da República.

Campinas: Editora da Unicamp. 2007.

PEIXOTO, Afrânio.

Psicopatologia forense. Rio de Janeiro: Francisco Alves. 1916.

PRANDO, Camila C.

O debate na Revista de Direito Penal (1933-1936): fundamentos da defesa social na cultura jurídicopenal. In: Seminário Nacional de Sociologia Política, 2., 2010, Curitiba. Anais... Curitiba: Programa de Pós-graduação em Sociologia, Programa de Pós-graduação em Ciência Política/ Universidade Federal do Paraná. p.3-24. 2010.

RODRIGUES, Raimundo Nina.

As raças humanas e a responsabilidade penal no Brasil. Rio de Janeiro: Guanabara. [1894]. 1933.

SKALEVAG, Svein Atle.

The matter of forensic psychiatry: a historical enquiry. Medical History, v.50, n.1, p.49-68. 2006.

SONTAG, Ricardo.

"A eloquência farfalhante da tribuna do júri": o tribunal popular e a lei em Nelson Hungria. Revista de História, v.28, n.2, p.267-302. 2009.

TORRES, Magarinos.

Jurisprudência. Homicídio passional com tentativa de suicídio. Arquivos do Manicômio Judiciário do Rio de Janeiro, ano 3, p.102-105.1932.

TORRES, Magarinos. Jurisprudência. Sentença do juiz Magarinos Torres. Arquivos do Manicômio Judiciário do Rio de Janeiro, ano 1, p.228-231. $1^{\circ}$ sem. 1930.

WEIJERS, Ido.

Delinquency and law. In: Jansz, Jeroen; Drunen, Peter Van (Ed.). A social history of psychology. Oxford: Blackwell. p.195-219. 2004.

\section{$\rightarrow \rightarrow \rightarrow<<$}

